\title{
Erratum to: Motive-Oriented Psychotherapeutic Relationship Facing a Patient Presenting with Narcissistic Personality Disorder: A Case Study
}

Ueli Kramer · Laurent Berthoud · Sabine Keller • Franz Caspar

Published online: 12 October 2013

(c) Springer Science+Business Media New York 2013

Erratum to: J Contemp Psychother

DOI 10.1007/s10879-013-9249-5

Unfortunately, the corresponding author of the article has overlooked to acknowledge the funding information in the original publication. The acknowledgment section is presented in this erratum.

Acknowledgments This research was supported by SNSF and funded by Grant No: 100014_134562/1.

The online version of the original article can be found under doi:10.1007/s10879-013-9249-5.

U. Kramer $(\bowtie) \cdot$ L. Berthoud · S. Keller

Department of Psychiatry-CHUV, Institute of Psychotherapy,

University of Lausanne, Av. D’Echallens 9, 1004 Lausanne,

Switzerland

e-mail: ueli.kramer@chuv.ch

L. Berthoud · F. Caspar

Clinical Psychology and Psychotherapy, University of Bern,

Bern, Switzerland 